\title{
Problem-based Learning vs Lectures-Comparison of Academic Performances among Dental Undergraduates in India: A Pilot Study
}

\author{
${ }^{1} \mathrm{~K}$ Rekha, ${ }^{2} \mathrm{~S}$ Naganandini, ${ }^{3}$ Shruthi Eshwar, ${ }^{4}$ Supriya Manvi, ${ }^{5} \mathrm{Joji}$ Markose
}

\begin{abstract}
Introduction: Effective teaching is critical for student learning, especially in professional field, such as dentistry. To cope with the dynamic state of society, the changing pattern of diseases, a clear understanding of the links between basic sciences, technology, and health care systems are crucial. Future health care provider's education system should encourage the development of learning characteristics, such as critical thinking and problem-solving. Problem-based learning (PBL) is one such method.
\end{abstract}

Aims and objectives: To evaluate the efficacy of PBL vs lecture method of teaching among the final-year dental undergraduates.

Materials and methods: A comparative study with 38 finalyear dental students, 19 students in PBL and 19 students in lecture groups were undertaken. The PBL group was further divided into three smaller groups. Both the groups were given a topic from the undergraduate curriculum of Public Health Dentistry prescribed by Dental Council India (DCI) and were assessed for their academic performances through an internal assessment examination.

Results: Both the groups consisted of higher number of females. Mean marks obtained by PBL group was $6.63 \pm 1.80$, which was significantly higher as compared with the lecture group which was $4.84 \pm 1.17\left(p=0.001^{* *}\right)$.

Conclusion: Students in PBL group showed better academic performance as compared with students in the lecture group.

Keywords: Academic performances, Dental students, Problembased learning

\footnotetext{
${ }^{1}$ Senior Lecturer, ${ }^{2}$ Professor and Head, ${ }^{3}$ Reader, ${ }^{4}$ Professor ${ }^{5}$ Private Practitioner

${ }^{1,3}$ Department of Public Health Dentistry, Karnatak Lingayat Education Society, Dental College and Hospital, Bengaluru Karnataka, India

${ }^{2}$ Department of Public Health Dentistry, NIMS University, Jaipur Rajasthan, India

${ }^{4}$ Department of Prosthodontics, Karnatak Lingayat Education Society, Dental College and Hospital, Bengaluru, Karnataka India

${ }^{5}$ Department of Implantology, Cosmo French Medical Center Sharjah, United Arab Emirates

Corresponding Author: K Rekha, Senior Lecturer, Department of Public Health Dentistry, Karnatak Lingayat Education Society Dental College and Hospital, Bengaluru, Karnataka, India Phone: +919731530115, e-mail: rao.rekha95@gmail.com
}

How to cite this article: Rekha K, Naganandini S, Eshwar S, Manvi S, Markose J. Problem-based Learning vs LecturesComparison of Academic Performances among Dental Undergraduates in India: A Pilot Study. World J Dent 2017; 8(1):59-66.

\section{Source of support: Nil \\ Conflict of interest: None}

\section{INTRODUCTION}

Student learning in any field, especially in professional fields, such as dentistry and medicine effective teaching, is very critical. In these fields teachers are usually expert clinicians who have limited or no prior formal teaching training. In these professional fields teachers are produced by chance rather than by training or design. The knowledge and technical skills of the professionals is presumed to be adequate enough for effective teaching in these professions which in turn might affect the student learning. ${ }^{1}$

In the past decade, dental education has been under pressure to change in the face of rapid expansion of knowledge, enhanced community expectations, and stakeholders' concerns. There have been repeated calls for a more contextual environment for student learning and to foster lifelong learning within dentistry. ${ }^{2}$

Increasingly, professional education programs are recognizing the need for professionals to be able to solve ill-structured problems and are incorporating instructional experiences into their curricula to help students develop problem-solving skill. One such instructional method is problem-based learning (PBL). ${ }^{3}$

New curricula, often based on principles of interactive and PBL, have been introduced in some of the medical and dental schools globally in an attempt to address these demands. In some situations, traditional didactic teaching curricula have been replaced entirely with student-centered learning ("pure PBL"), whereas others have adopted hybrid forms integrating both didactic and PBL approaches to varying degrees. ${ }^{1}$

To cope with the dynamic state of society, the changing pattern of diseases, and rapidly advancing technology, a clear understanding of the links between basic sciences, technology assessment, and health care systems is crucial. 
In the future, we will need to be able to search for correct information in a cost-effective manner and to use accepted methods of statistical inference to make informed decisions and proper estimates. The vigorous trend toward evidence-based health care can be seen as a reflection of changing health care.

To ensure that future health workers would meet the needs of the changing environment, reports made recommendations that health education should encourage the development of learning characteristics, such as critical thinking, decision making, active and autonomous learning, and problem-solving. Several medical schools have determined that PBL is an educational strategy that would aid in the development of such characteristics. ${ }^{4}$

Hence, in our present study, we would like to evaluate the efficacy of PBL $v$ s lecture method of teaching among the final-year dental undergraduate of The Oxford Dental College, Bengaluru.

\section{MATERIALS AND METHODS}

A comparative efficacy study was conducted to evaluate the efficacy of PBL $v$ s lecture method of teaching among the final-year undergraduate students of The Oxford Dental College, Bengaluru. The study protocol was reviewed and approved by Ethical Review Board, The Oxford Dental College and Hospital, Bengaluru. Students who agreed to participate in the study provided informed consent for participating in the PBL sessions.

\section{Study Population}

Participants for the study were final-year undergraduate students of The Oxford Dental College, Bengaluru. The study sample consisted of 38 final-year undergraduate students (total strength of final-year BDS students was 45 , based on the exclusion criteria 38 were included for the study). They were randomly allocated to PBL group and the lecture group by lottery method. Each group consisted of 19 students. The PBL group was further divided into three smaller groups, consisting of 6 members in two groups and 7 members in one group.

\section{Inclusion Criteria}

Final-year dental undergraduates who gave their consent to participate in the study.

\section{Exclusion Criteria}

- Students who did not attend all the sessions in PBL group and who did not attend both the lecture classes in lecture group were excluded from the study.

- Students who did not attend the test conducted at the end of PBL sessions and lecture class.

\section{SCHEDULE OF THE STUDY}

\section{PBL Group}

\begin{tabular}{|c|c|c|}
\hline Days & $\begin{array}{l}\text { Group } \\
\text { addressed }\end{array}$ & Activity done \\
\hline 1 & Whole group & Introductory lecture on PBL \\
\hline \multirow[t]{4}{*}{2} & Small group & Problem presented to the group \\
\hline & & Analyze the problem \\
\hline & & Formulating the working hypothesis \\
\hline & & $\begin{array}{l}\text { Formulating the learning objectives to } \\
\text { explain the problem by the students }\end{array}$ \\
\hline \multirow[t]{2}{*}{3} & Small group & $\begin{array}{l}\text { Each student collects information on } \\
\text { the learning objectives from different } \\
\text { sources }\end{array}$ \\
\hline & & $\begin{array}{l}\text { Each students explains about the } \\
\text { information they have collected and rest } \\
\text { of the group critically evaluates it }\end{array}$ \\
\hline 4 & Small group & $\begin{array}{l}\text { Conclusion of the problem with review } \\
\text { of the students' current understanding } \\
\text { and abilities, with integration of learning } \\
\text { achieved through their problem } \\
\text { exploration and independent study }\end{array}$ \\
\hline
\end{tabular}

\section{Lecture Group}

\begin{tabular}{lll}
\hline Days & $\begin{array}{l}\text { Group } \\
\text { addressed }\end{array}$ & Activity done \\
\hline 1 & Whole group & Lecture class on dental ethics \\
2 & Whole group & $\begin{array}{l}\text { Lecture class on dental ethics completed. } \\
\text { At the end of the class, a small activity } \\
\text { was done to assess the understanding } \\
\text { by the students }\end{array}$ \\
& & \\
\hline
\end{tabular}

\section{STUDY PROCEDURE}

The PBL and the lecture groups were taught the same topic, i.e., dental ethics from undergraduate curriculum of Public Health Dentistry prescribed by the Rajiv Gandhi University of Health Sciences (RGUHS) by a common facilitator. Only one facilitator taught both the groups to prevent bias and maintain uniformity in dissemination of knowledge. Each group selected their moderator who would in turn report to the facilitator.

The module for the PBL group is as follows: Day 1: Introduction to PBL.

Whole group: Introductory lecture on PBL which consisted of:

- Objectives, key features, and steps in PBL

- Video of a group of students engaged in PBL process The whole group was divided into smaller groups. Each group consisted of six to eight members.

For each small group the moderator was selected.

Day 2: 1st session of PBL 45 minutes session

Small group

- Problem is presented to the students which simulates the clinical scenario.

- Students clarify difficult or new terms in the problem given. 
- Students identify any problems or phenomena to be explained.

- Analyze the problem, formulating the working hypothesis and learning objectives to explain the problem.

- Students and facilitator decide what should be discussed in the next session of PBL and what are means or sources of collecting information with regards to problem and learning objectives.

- Students and facilitator also decide on when and where to meet for the next PBL session.

Working hypothesis: To know about ethics in clinical practice in detail.

\section{Learning Objectives}

- Meaning and definition of the word ethics, difference between morals, values, virtue, and ethics

- History of medical ethics

- Why code of dental ethics?

- Theories of ethics

- Ethical rules for dentists prescribed by Dental Council of India (DCI)

- Ethical principles

- Consent - types

- Nuremberg code and Helsinki's declaration

- Duties and obligations of the dentist toward patient, professional colleagues, and society.

- Doctor-patient relationship - Contract law

- Express terms

- Unethical practices.

Day 3: 2nd session of PBL 1 hour session Small group:

- Recap of what was done in the previous session

- Each student has collected information on the learning objectives by various sources

- Each student explains about the information they have collected and rest of the group critical evaluates it

- The facilitator gives a conclusion for the discussion based on the information collected by the students and also clears any doubts in understanding of the students.

Day 4: 3rd session of PBL 1 hour session

Small group:

- Similar to session 2 including conclusion of the problem with review of the students' current understanding and abilities, with integration of learning achieved through their problem exploration and independent study.

The "problems" that is the real-life scenario are presented to each smaller group in the PBL group, and the solutions were prepared by the facilitator in advance so that it could facilitate in the group discussion. At the end of PBL session, all the students completed a module evaluation sheet which was considered as one of the methods of assessment of the PBL group (ANNEXURE 1). Lecture group: The lecture group also consisted of 19 members.

The students were taught the "dental ethics" with teaching learning media as:

- Audiovisual aid

- LCD-projector

- White board Objectives of lecture class were:

- Students understand ethics in clinical practice in detail

- Students should know about the principles of ethics and their application in clinical practice

- They should understand duties and obligations of the dentist toward patient, professional colleagues, and society. The lecture class was taken for duration of 2 hours, which included two lecture classes 1 week apart.

\section{EVALUATION OF PBL AND LECTURE METHOD OF TEACHING}

The students were evaluated during the PBL class and lecture class through observation of students and the end of the class through response to question through asking questions.

At the end of PBL session and the lecture class, the students gave a test on the topic dental ethics for which a prior notice was given to both the groups. The facilitator was not involved in conducting or the assessment of the test for both the groups. The question paper consisting of 10 multiple choice questions (ANNEXURE 2) for the test was evaluated by a faculty member who was not aware of the distribution of the students in the PBL and the lecture groups. Outcomes of the PBL and lecture method of teaching among the final-year undergraduate students were assessed through their performances in the test mentioned earlier.

\section{Statistical Analysis}

Descriptive statistical analysis has been carried out in the present study. Results on continuous measurements are presented on mean \pm SD (Min-Max) and results on categorical measurements are presented in Number (\%). Significance is assessed at 5\% level of significance. Student's t-test (two-tailed, independent) has been used to find the significance of study parameters on continuous scale between the two groups (intergroup analysis) on metric parameters. Leven test for homogeneity of variance has been performed to assess the homogeneity of variance. Chi-square/Fisher's exact test has been used to find the significance of study parameters on categorical scale between two or more groups. 


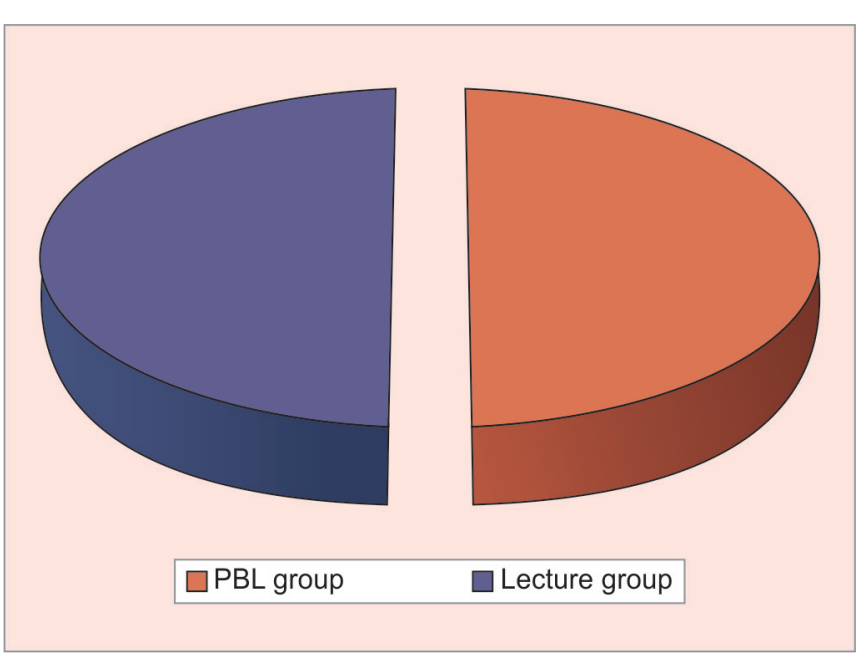

Graph 1: Distribution of the study population into PBL group and lecture group

\section{Significant Figures}

+Suggestive significance ( $p$-value: $0.05<\mathrm{p}<0.10$ )

*Moderately significant ( $\mathrm{p}$-value: $0.01<\mathrm{p} \leq 0.05$ )

**Strongly significant ( $p$-value: $p \leq 0.01$ )

\section{RESULTS}

The study included 5 (26.3\%), 8 (42.1\%) male subjects in PBL and lecture groups respectively and 14 (73.7\%) and $11(57.9 \%)$ female subjects in PBL and lecture groups respectively (Graph 1).

Module evaluation was done for the assessment of student's performances in the PBL group. When students were asked about participation in group, showing sensitivity to the group needs as well as self-needs and demonstrating aspirations of all members of the group their responses ranged from good to very good (3.32 \pm 0.48 ), the responses for the learning skills ranged from good to magnificent $(3.47 \pm 0.61)$, for reasoning the responses were good to very good $(3.42 \pm 0.51)$, and when students were asked about their ability to provide constructive feedback to the group promoting the group's ability to learn their responses ranged from good to magnificent $(3.74 \pm 0.81)$ (Table 1).

When students were asked that in which area they felt they could have done better, their responses were

Table 1: Distribution of the study population based on module evaluation in PBL group

\begin{tabular}{lll}
\hline & \multicolumn{2}{c}{ Score } \\
\cline { 2 - 3 } Module evaluation & Min-Max & Mean \pm SD \\
\hline Group skills & $3-4$ & $3.32 \pm 0.48$ \\
Learning skills & $3-5$ & $3.47 \pm 0.61$ \\
Reasoning & $3-4$ & $3.42 \pm 0.51$ \\
Feedback & $3-5$ & $3.74 \pm 0.81$ \\
Group performance & $3-5$ & $3.58 \pm 0.69$ \\
Interest of case & $3-5$ & $4.21 \pm 0.63$ \\
\hline
\end{tabular}

varied from preparation for class, collecting the information properly, concluding the problem, in reasoning and application, discussion in small group, open to others suggestion, communication, group learning. Similarly about the area where they felt they did a good job, their responses ranged from doing work on time, reasoning, solving the problem, discussing in the group, actively participating, critically evaluating the problem, correlating the facts, and application aspect.

Group performance was rated as good to magnificent $(3.58 \pm 0.69)$ and whether the problem given to them was interesting enough, the response ranged from ordinary to highly interesting $(4.21 \pm 0.63)$.

The min-max range of marks obtained in PBL group was 3 to 9 out of 10 (mean $\pm \mathrm{SD}=6.63 \pm 1.80)$ and in the lecture group was 2 to 6 (mean $\pm \mathrm{SD}=4.84 \pm 1.17)$. The marks obtained by students in PBL group were significantly higher than the students in the lecture group $(\mathrm{p}=0.001)$ (Table 2$)$.

\section{DISCUSSION}

India has a good number of dental colleges and institutes which are known for world-class facilities like modern technology and equipments, talented teachers, top class infrastructure. The Dentist Act 1948, Dental education and dentistry as a profession, was regulated throughout India. There are more than 289 dental institutes all over India. A 5-year dental education, which includes 5,200 curriculum hours, leads to the BDS degree in India. ${ }^{5}$

Total number of hours dedicated for didactic lecture classes is 1,590 and for the practical classes it is 1,540 in the undergraduate curriculum prescribed by DCI of India. Total number of hours dedicated for didactic lecture classes is 60 and for the practical classes it is 200 for final-year BDS for the specialty of public health dentistry prescribed by DCI of India. ${ }^{6}$

Source: Implementation of DCI Revised BDS Course (3rd Amendment) Regulations, 2011, New Delhi.

However, the dental curriculum in most schools is taught in a traditional, subject-wise fashion predominantly through didactic lectures. Assessment continues

Table 2: Distribution of study population based on academic performances in PBL group and lecture group

\begin{tabular}{lll}
\hline Marks & $P B L$ & Lecture \\
\hline Min-max & $3-9$ & $2-6$ \\
Mean \pm SD & $6.63 \pm 1.80$ & $4.84 \pm 1.17$ \\
95\% Confidence & $5.76-7.50$ & $4.28-5.40$ \\
interval $(\mathrm{Cl})$ & \\
Inference & Marks obtained is significantly more in \\
& PBL group compared with lecture group \\
& with $\mathrm{p}=0.001^{* *}$ & \\
\hline${ }^{* *} \mathrm{p}$ value strongly significant
\end{tabular}


to mainly test factual knowledge and recall. The question sets for the theory examination are usually repeated ad nauseam. The students prepare for the theory examination by going through the important questions of the previous years. In the practical examination, the students have often been shown the problems/charts.

The DCI has recommended establishing new pedagogical methodologies in the universities, which define the roles of students and teachers and highlight the students' formation, with the goal of making them responsible for their own learning. The main objective is to create educational models that allow the transformation of students to "world citizens," without losing their cultural roots and national identities. ${ }^{8}$

The National Assessment and Accreditation Council (NAAC) is an autonomous body established by the University Grants Commission (UGC) of India to assess and accredit institutions of higher education in the country.

Problem-based learning method of education is given highest level of importance in NAAC evaluation. It also assess the total number of PBL classes conducted for a particular topic and based on these criteria provide the overall accreditation points.

The NAAC recommends the use of PBL in higher education as PBL involves development of effective clinical problem-solving, self-directed learning, team, and interpersonal skills, which in turn improves the quality of learning and understanding and hence better performances of students at the academic level (www.naac.gov.in/).

Studies conducted by Rich et $\mathrm{al}_{1}^{9}$ Pau et $\mathrm{al}_{1}{ }^{10}$ Lahijani and Kateb, ${ }^{11}$ Moreno-López et al ${ }^{12}$ have shown that dental students improved in their academic performances after teaching with PBL pedagogy. Problem-based learning is implemented in dental schools of Europe (Sweden, The Netherlands, Norway, and the UK), Asia (Hong Kong, Singapore, and Thailand), Australia, New Zealand, USA, and Canada successfully. There are no reports where PBL implementation has been stopped or withdrawn from any schools where this pedagogy is employed fully or partly.

Problem-based learning pedagogy has not been implemented in India in the undergraduate curriculum despite its advantages. Hence, the present study attempts to compare the efficacy of the PBL method and lecture method to assess whether PBL is in any way better than the traditional learning methods.

In the present study, only final-year students were included as they were familiar with the topics in Public Health Dentistry and the students could appreciate the importance of the topic from both examination and application in day-to-day practice point of view.

The present study evaluated the module of PBL method among the PBL group students, and the students graded their performances in a group, i.e., group skills and reasoning skills from good to very good, learning and feedback skills as good to magnificent. They also rated their overall group performance as good to magnificent. Students felt that the clinical scenario or the problem given to them ranges from ordinary to highly interesting as far as the interest was considered.

Study conducted by Pau et $\mathrm{al}^{10}$ evaluated students perception about the achievement of the skills in problemsolving, collecting data, communication, leadership, presentation, and working with others. Students perceived that they could achieve all these skills and enhance their overall professional skills which are important for practicing as dentists through the PBL approach.

When students were asked about the area where they did a good job, their responses ranged from doing work on time, reasoning, solving the problem, learning better, answering the questions, providing resources, discussing in the group, actively participating, critically evaluating the problem, understanding the problem, correlating the facts, and application aspect. The students showed such varied responses as these were open-ended questions, and since responses were individual perceptions, they varied greatly.

In the present study, students in the PBL group performed significantly better than students in the lecture group in the application-based questions. The reason for better performance in the application-based questions is due to participation in group and reasoning, critical thinking, decision-making, active, and autonomous learning during the PBL sessions.

Problem-based learning students obtained a good mean mark $(6.63 / 10)(p=0.001)$ in the examination, which was significantly higher than the mean mark achieved by those receiving conventional lectures.

Study by Rich et $\mathrm{al}^{9}$ showed slightly superior academic results in a PBL group than in a group receiving lectures, but the difference did not reach significance. Similarly study conducted by Moreno-López et a $1^{12}$ showed that PBL participants obtained higher grades compared to those receiving lectures only $(\mathrm{p}<0.05)$ and they concluded that PBL is a teaching-learning methodology that improves student academic results.

The reasons for better performance of students in PBL group could be due to learning in the small groups and individual attention given to each student by the facilitator. The other reason could also be that more time dedicated by the students and facilitator toward problems simulating real-life situations. The PBL approach integrates knowledge and skills of the students in the problem-solving and enhances the self-directed learning and this could have influence on the student's performance.

In our present study, we saw that PBL method to be more demanding in terms time dedicated as well as efforts to learn and collect relevant information as compared with 
lecture method. This could also be one of the reasons for better performance by students in the PBL group.

The present study involved only 38 students and was conducted for a lesser duration of time and further studies need to be conducted on larger populations and longer duration of time to support the findings of the present study.

\section{CONCLUSION}

This study was conducted with the aim to evaluate the efficacy of PBL vs lecture method of teaching among the final-year undergraduate students.

- The present study evaluated the module of PBL method, and the students graded their performances like:

- Group skills and reasoning skills from good to very good
- learning and feedback skills as good to magnificent

- Overall group performance as good to magnificent.

- Students in PBL group performed significantly better than students in Lecture group in the application-based questions. The reason for better performance in the application-based questions is due to participation in group and reasoning during PBL sessions.

- Problem-based learning students obtained a good mean mark (6.63/10) in the examination, which was significantly higher than the mean mark achieved by those receiving conventional lectures. Overall, the students in the PBL group performed better than students in the lecture group.

\section{ANNEXURE 1}

\section{Module Evaluation}

\section{PBL Process Evaluation}

On a scale of a 1 to 5 score $(1=$ Very poor; 5 = Magnificent! $)$ how do you feel that you have performed in this problem case? (Be objective!)

A. Group skills: I actively participated in the work of the group showing sensitivity to group needs as well as self needs and demonstrating respect for the aspirations of all members of the group.
1. Very poor
2. Poor
3. Good
4. Very good
5. Magnificent

B. Learning skills: I effectively identified group and individual learning needs and identified the appropriate learning resources.
1. Very poor
2. Poor
3. Good
4. Very good
5. Magnificent

C. Reasoning skills: I demonstrated an ability to critically evaluate information, to synthesize, and to critically appraise data.
1. Very poor
2. Poor
3. Good
4. Very good
5. Magnificent

D. Feedback skills: I demonstrated an ability to provide constructive feedback to the group, promoting the group's ability to learn.

1. Very poor

2. Poor

3. Good

4. Very good

5. Magnificent AND (One sentence only)

E. I could do better in the following:

F. I feel I did a good job in the following:

G. Overall I would rate our group performance in this case as:

H. In terms of "Interest" I would rate this case as:

$1=$ Very dull

$2=$ Dull

$3=$ Ordinary

$4=$ Interesting

$5=$ Highly interesting 
ANNEXURE 2

Department of Public Health Dentistry

The Oxford Dental College Hospital and Research Centre, Bengaluru

THEORY INTERNAL ASSESSMENT - AUGUST 2012

FINAL YEAR BDS

$\begin{array}{ll}\text { Max.Marks: } 10 & \text { Time allotted: } 15 \text { min } \\ \text { Roll No: } & \end{array}$

Instructions:

Answer all questions.

Each question carries one mark.

Please choose the most appropriate answer.

If more than one alternative is marked, it will be considered as a wrong answer.

\section{QUESTIONS}

1. Ethics can be best defined as: - MEMEORY
a. A set of rules to be followed by a profession
b. A code of conduct which the members of an association are expected to follow
c. A set of unwritten rules and guidelines
d. The philosophy of human conduct

2. In which of the following conditions informed consent is not required? - APPLICATION
a. All major diagnostic procedure
b. Surgical operations
c. General anesthesia
d. Determining prognosis

3. Code of ethics for dentists was framed by Dental Council of India in: MEMORY
a. 1948
b. 1954
c. 1976
d. 1982

4. Paternalism in health care can take the form of: APPLICATION
a. Working in the best interest of the patient
b. Helping patient in making choices
c. Withholding information
d. Discuss carefully the course of action

5. Veracity means: MEMORY
a. Justice
b. Voluntary
c. Comprehending
d. Truthfulness

6. Code of ethics framed by Dental Council of India based on: MEMORY
a. Descriptive theory
b. Deontological theory
c. Puritan ethics
d. Prescriptive theory

7. Example of unethical practice: APPLICATION/REASONING

a. Obtaining informed consent

b. Dentist advertising for job vacancy in his/her office

c. Undercutting of charges in order to solicit patients

d. Transferring communications and records pertaining to patient care to referring dentist

8. Following are the duties of the patient toward the dentist except: APPLICATION
a. Must disclose all information that may be necessary for proper diagnosis
b. Must follow home care instructions
c. Should notify the dentist of a change in health status
d. Must be skeptical about any relevant investigations required for the treatment

9. Express term consists of all the following except: MEMORY a. One in which both parties are in agreement.
b. Define items, such as fee, the treatment, and the manner in which payments are to be made.

c. Being stated in a distinct and explicit language.

d. Guarantees made by the patient

10. Fresh General dentist with limited surgical skills considers performing a biopsy herself rather than referring the patient to an oral and maxillofacial specialist. Here the extent of tissue removed, the skills of procedure may vary when done by the fresher compared with that of specialist. Which principle is violated here: REASONING
a. Non maleficence
b. Justice
c. Truthfulness
d. Autonomy 


\section{REFERENCES}

1. Schönwetter DJ, Lavigne S, Mazurat R, Nazarko O. Students' perceptions of effective classroom and clinical teaching in dental and dental hygiene education. J Dent Educ 2006 Jun;70(6):624-635.

2. McGrath C, Comfort MB, Luo Y, Samaranayake LP, Clark CD. Application of an interactive computer program to manage a problem-based dental curriculum. J Dent Educ 2006 Apr;70(4):387-397.

3. Lohman MC, Finkelstein M. Designing cases in problembased learning to foster problem-solving skill. Eur J Dent Educ 2002 Aug;6(3):121-127.

4. Rohlin M, Petersson K, Svensäter G. The Malmö model: a problem-based learning curriculum in undergraduate dental education. Eur J Dent Educ 1998 Aug;2(3):103-114.

5. Tandon S. Challenges to the oral health workforce in India. J Dent Educ 2004 Jul;68(7):28-33.

6. Implementation of DCI Revised 80S Course (3rd Amendment) Regulations; 2011. Dental Council of India, Report.
7. Shankar PR. Integrating subjects through problem-based learning: a South Asian perspective. Med Educ Online 2006;12:1-2.

8. Kohli A. Problem based learning in dentistry - an answer to future challenges. Dentistry India 2008 Mar;2(2).

9. Rich SK, Keim RG, Shuler CF. Problem-based learning versus a traditional educational methodology: a comparison of preclinical and clinical periodontics performance. J Dent Educ 2005 Jun;69(6):649-662.

10. Pau AK, Collinson S, Croucher R. Dental students' evaluation of 2 community-oriented PBL modules. Eur J Dent Educ 1999 Nov;3(4):159-166.

11. Lahijani S, Kateb R. The effect of PBL and film showing, frequent quizzes and lecture-based method on short-term performance of dentistry students. J Med Educ 2004 Winter;4(2):77-80.

12. Moreno-LópezLA,Somacarrera-PérezML,Díaz-RodríguezMM, Campo-Trapero J, Cano-Sánchez J. Problem-based learning versus lectures: comparison of academic results and time devoted by teachers in a course on Dentistry in Special Patients. Med Oral Patol Oral Cir Bucal 2009 Nov 1;14(11):e583-e587. 